\title{
VALOR NUTRICIONAL DO FENO DE SOJA EM DIFERENTES ESTÁDIOS DE MATURAÇÃO
}

MATOS, Murilo Delmônico de ${ }^{1}$

\begin{abstract}
RESUMO: O experimento foi realizado no Sítio das Acácias II, área experimental da Faculdade "Dr. Francisco Maeda" - FAFRAM, no município de Ituverava/SP, na safra 2016/2017. Objetivou-se verificar a qualidade do feno de soja em diferentes estádios de maturação. O material foi cortado sempre às 8 horas da manhã, pesados e expostos ao sol para secagem, sendo posteriormente pesados. Após a secagem as amostras foram enviadas ao laboratório da mesma instituição para ser feita a análise bromatológica para obter as porcentagens de matéria seca (MS), proteína bruta (PB), fibra em detergente neutro (FDN) e fibra em detergente ácido (FDA). Os dados qualitativos coletados foram submetidos à análise de variância em um delineamento inteiramente casualisado (DIC) com cinco tratamentos e quatro repetições e as médias comparadas pelo teste de Tukey a 5\% de margem de erro. O estádio de maturação R6 apresentou a melhor opção de corte para fenação no município de Ituverava-SP.
\end{abstract}

Palavras-chave: Maturação da soja. Nutrição animal. Glycine max. Análise bromatológica.

SUMMARY: The experiment was carried out at Sítio das Acácias II, an experimental area of the "Dr. Francisco Maeda "- FAFRAM, in the municipality of Ituverava / SP, in the 2016/2017 harvest. The objective of this study was to verify the quality of soybean hay at different maturation stages. The material was always cut at 8 o'clock in the morning, weighed and exposed to the sun for drying, and later weighed. After drying the samples were sent to the laboratory of the same institution to perform the chemical analysis to obtain the percentages of dry matter (DM), crude protein (CP), neutral detergent fiber (NDF) and acid detergent fiber (FDA) . The qualitative data were submitted to analysis of variance in a completely randomized design (DIC) with five treatments and four replicates and the means compared by the Tukey test at 5\% margin of error. The development stage R6 presented the best cutting option for fenação in the municipality of Ituverava-SP.

Keywords: Soy maturation. Animal nutrition. Glycine max. Bromatological analysis.

\section{INTRODUÇÃO}

A soja é, uma das espécies mais cultivadas no Brasil, sendo a produção de grãos a quase totalidade da sua utilização, tanto na alimentação animal como no consumo humano. As primeiras cultivares de soja, trazidas para o Brasil em 1882, foram estudadas com vistas ao seu potencial como planta forrageira (EMBRAPA, 2004). Apesar de não ser esta a principal forma de exploração dessa cultura, a planta de soja apresenta-se como ótima alternativa para a obtenção de volumoso, com considerável valor protéico. Em contrapartida, a utilização desta oleaginosa para forragem tem sido muito pouco difundida, apesar da qualidade nutritiva e de seu alto potencial de produção (REZENDE et al., 2011).

O processo de fenação consiste em conservar a planta obtida, por meio do corte e desidratação, reduzindo seu teor de umidade de $70 \%$ a $90 \%$ para $12 \%$ a $15 \%$, utilizando-se de

\footnotetext{
${ }^{1}$ Faculdade Doutor Francisco Maeda
} 
processos naturais, como calor do sol e vento e ou artificiais, com o uso de secadores, podendo, dessa forma, ser armazenada com perdas mínimas de seu valor nutritivo, o que aproxima o feno, qualitativamente, do material que lhe deu origem. Tem sido definido como um meio de produzir um produto estável, de adequado valor nutritivo, com um mínimo de perdas e com um custo razoável de produção (CRUZ, 1997).

A qualidade da forragem, ou seu valor alimentar, pode ser melhor definida como a capacidade do alimento em promover a produção animal e pode ser expresso pelo produto entre o valor nutritivo da forragem e o potencial de consumo desta forragem pelos animais. $\mathrm{O}$ valor nutricional de uma forragem é determinado pelo seu conteúdo químico e pela transformação desses em nutrientes necessários ao animal (REIS; RODRIGUES, 1993).

Além das inúmeras vantagens da utilização da soja como forrageira, pode-se destacar a altura de planta favorável ao manejo e, principalmente, cultivares adaptadas às adversidades climáticas, proporcionando maior rendimento por ocasião da colheita (EVANGELISTA, 1986).

A soja se utilizada na forma de feno, apresenta, ainda como vantagem, a possibilidade de uso de outras culturas em sucessão, devido ao pequeno tempo de permanência no campo (GRIS, 2008).

Segundo Vilela (2017), o estádio de crescimento da planta é que determina o seu valor nutritivo. Plantas forrageiras durante o crescimento vegetativo apresentam alto valor nutritivo e à medida que passam do crescimento vegetativo para o reprodutivo (floração) este valor decresce acentuadamente. Contudo cortar uma planta muito jovem não é interessante, pois a produção de matéria seca cresce segundo o modelo sigmoidal com a idade da planta e ainda por ela conter um teor de água muito elevado.

Diante do exposto, objetivou-se verificar a qualidade do feno de soja em diferentes estádios de maturação.

\section{REVISÃO DE LITERATURA}

\subsection{Feno de leguminosa}

A capacidade de suporte das pastagens, relativamente alta e a qualidade satisfatória da forragem disponível possibilitam níveis de produtividade razoáveis no período das águas. Todavia, durante a seca, esses níveis de produção caem, em razão da baixa disponibilidade de pasto, em quantidade e qualidade. Como conseqüência da estacionalidade na produção de forragens, o pecuarista se vê forçado a reduzir a taxa de lotação animal durante o período seco, com o objetivo de equilibrar o suprimento de forragem com a demanda de alimento pelo rebanho, 
a não ser que alguma medida de suplementação volumosa ou concentrada seja empregada (MARTHA JÚNIOR; CORSI, 2001).

A suplementação dos animais durante o período de inverno, através de forragens conservadas como o feno é uma prática viável, relativamente fácil e, neste caso, os fenos de leguminosas apresentam teores mais elevados em proteína e cálcio que fenos de gramíneas (VILELA, 1984).

\section{$1.2 O$ processo de fenação}

O processo de fenação consiste em conservar a planta obtida, por meio do corte e desidratação, reduzindo seu teor de umidade de $70 \%$ a $90 \%$ para $12 \%$ a $15 \%$, utilizando-se de processos naturais, como calor do sol e vento e ou artificiais, com o uso de secadores, podendo, dessa forma, ser armazenada com perdas mínimas de seu valor nutritivo, o que aproxima o feno, qualitativamente, do material que lhe deu origem. Tem sido definido como um meio de produzir um produto estável, de adequado valor nutritivo, com um mínimo de perdas e com um custo razoável de produção (CRUZ, 1997).

Costa et al. (2000) discorre que existem dois processos de confecção do feno, que são eles: processo artesanal ou manual, utilizado para pequenas quantidades de feno, e processo mecanizado, utilizado para grandes quantidades de feno.

Segundo Costa et al. (2000), no processo artesanal ou manual, todas as operações são feitas manualmente, utilizando para o corte da forrageira podões, alfanjes, motossegadeiras ou roçadeira costal motorizada. Nos processos de revolvimento e viragem da forragem, o mesmo é feito utilizando garfo. Ao final do processo o feno é recolhido do campo e armazenado no galpão ou em montes de feno (medas) no próprio campo.

Segundo Costa et al. (2000), no processo mecanizado, que é utilizado quando se tem grandes quantidades de feno, são utilizados a segadeira para o corte; o ancinho para as operações de espalhamento, viragem e enleiramento da forragem; enfardadeira automática, que recolhe o feno enleirado e já confecciona os fardos (cilíndricos ou retangulares). Graças ao processo mecanizado, têm-se um melhor aproveitamento das áreas, aumentando-se o rendimento e gerando uma economia de mão-de-obra.

Segundo Costa et al. (2000), o corte deve ser feito em dias secos, onde não se tem previsão de chuvas, porque caso chova sobre a forrageira, a mesma irá demorar mais tempo para secar. Durante a secagem a umidade do feno deve ser inferior a $20 \%$, deve-se fazer a viragem da forragem cortada de uma à duas vezes ao dia, trazendo à superfície o material mais úmido até que a forragem seque bem, para isso deve-se repetir esta operação nos dias seguintes. Em seguida é feito o enleiramento e espera-se uma noite, no dia seguinte vira-se a leira formando leiras frouxas 
e uniformes (para maior circulação de ar e para facilitar o enfardamento). O ponto de feno é aquele onde você pega uma amostra com as mãos e as folhas estão quebradiças e o feno apresenta-se pouco maleável.

$\mathrm{O}$ armazenamento deve ser feito em barracões arejados, com os fardos sobre estrados de madeira para evitar o contato com o piso. Se a temperatura do feno se elevar ou houver presença de mofo, isso indica umidade excessiva do feno. Entretanto, o feno também pode ser guardado solto, porque o processo de enfardamento é muito trabalhoso e oneroso (COSTA et al., 2000).

Os custos de fenação podem ser estimados levando-se em conta as despesas com a produção de forragem mais os gastos com máquinas, equipamentos e mão-de-obra empregados no corte, viragem, recolhimento, transporte e armazenamento do feno (COSTA et al., 2000).

Consegue-se reduzir o custo de produção de feno mediante: (1) aumento da escala da produção, com menores custos dos equipamentos empregados; (2) maior produtividade da área, com maior aproveitamento de cada operação executada; (3) melhor qualidade da forragem, com menor dispêndio por unidade de nutriente disponível; (4) alta eficiência de produção, com menores perdas de forragem e obtenção de um produto de melhor qualidade (COSTA et al., 2000).

Para saber corretamente a qualidade de seu feno deve ser feita uma análise bromatológica do mesmo. Segundo Costa et al. (2000), nas avaliações químicas, o teor inicial de matéria seca é útil para predizer ou corrigir problemas de armazenamento; o teor de proteína bruta (PB) é uma boa medida da qualidade do feno visando ao balanceamento da dieta; o teor de fibra em detergente neutro dá idéia do consumo de feno, e o teor de fibra em detergente ácido guarda relação inversa com a digestibilidade.

A Tabela 1 apresenta uma proposta da Embrapa Gado de Leite para a avaliação das principais características utilizadas na classificação de fenos de gramíneas e leguminosas.

Tabela 1. Interpretação da análise da amostra de fenos - Embrapa Gado de Leite.

\begin{tabular}{l|c|c}
\hline \multirow{2}{*}{ Componentes } & \multicolumn{2}{c}{ Intervalos esperados* } \\
\cline { 2 - 3 } & Gramínea & Leguminosa \\
\hline Umidade (\%) & $20-15$ & $18-15$ \\
\hline Proteína Bruta & $8-16$ & $15-24$ \\
\hline Fibra em detergente neutro & $78-66$ & $54-38$ \\
\hline Fibra em detergente ácido & $43-30$ & $44-28$ \\
\hline Cinzas & $9-6.1$ & $10.2-8.9$ \\
\hline Cálcio & $0.26-0.4$ & $1.25-2.3$ \\
\hline Fósforo & $0.18-0.27$ & $0.20-0.35$ \\
\hline Magnésio & $0.13-0.21$ & $0.30-0.50$ \\
\hline Potássio & $1.3-1.2$ & $1.7-2.25$ \\
\hline Lignina & $7-4$ & $54-76$ \\
\hline NDT estimado \% & $43-61$ & 5 \\
\hline
\end{tabular}

Nucleus Animalium, v.10, n.1, maio 2018 


\subsection{Estádios de desenvolvimento da soja}

A soja como a maioria das culturas comerciais já foi estudada e separada em diferentes estádios de desenvolvimento, que são demonstrados na (Tabela 2) e (Tabela 3).

Tabela 2. Descrição sumária dos estádios vegetativos da soja.

\begin{tabular}{l|l|l}
\hline Estádio & Denominação & Descrição \\
\hline VE & Emergência & Cotilédones acima da superfície do solo \\
\hline VC & Cotilédone & Cotilédones completamente abertos \\
\hline V1 & Primeiro nó & Folhas unifolioladas completamente desenvolvidas \\
\hline V2 & Segundo nó & Primeira folha trifoliolada completamente desenvolvida \\
\hline V3 & Terceiro nó & Segunda folha trifoliolada completamente desenvolvida \\
\hline V4 & Quarto nó & Terceira folha trifoliolada completamente desenvolvida \\
\hline V5 & Quinto nó & Quarta folha trifoliolada completamente desenvolvida \\
\hline V6 & Sexto nó & Quinta folha trifoliolada completamente desenvolvida \\
\hline V... & $\ldots$ & $\ldots$ \\
\hline Vn & Enésimo nó & Ante-enésima folha trifoliolada completamente desenvolvida \\
\hline
\end{tabular}

Fonte: Adaptado de FARIAS et al. (Circular Técnica 48, 2007)

Tabela 3. Descrição sumária dos estádios reprodutivos da soja.

\begin{tabular}{|c|c|c|}
\hline Estádio & Denominação & Descrição \\
\hline R1 & Início do florescimento & $\begin{array}{l}\text { Uma flor aberta em qualquer nó do caule (haste } \\
\text { principal) }\end{array}$ \\
\hline $\mathrm{R} 2$ & Florescimento pleno & $\begin{array}{l}\text { Uma flor aberta num dos } 2 \text { últimos nós do caule com } \\
\text { folha completamente desenvolvida }\end{array}$ \\
\hline R3 & $\begin{array}{l}\text { Início da formação da } \\
\text { vagem }\end{array}$ & $\begin{array}{l}\text { Vagem com } 5 \mathrm{~mm} \text { de comprimento num dos } 4 \text { últimos } \\
\text { nós do caule com folha completamente desenvolvida }\end{array}$ \\
\hline $\mathrm{R} 4$ & $\begin{array}{l}\text { Vagem completamente } \\
\text { desenvolvida }\end{array}$ & $\begin{array}{l}\text { Vagem com } 2 \mathrm{~cm} \text { de comprimento num dos } 4 \text { últimos } \\
\text { nós do caule com folha complet amente desenvolvida }\end{array}$ \\
\hline R5 & $\begin{array}{l}\text { Início do enchimento } \\
\text { do grão }\end{array}$ & $\begin{array}{l}\text { Grão com } 3 \mathrm{~mm} \text { de comprimento em vagem num dos } 4 \\
\text { últimos nós do caule, com folha completamente } \\
\text { desenvolvida }\end{array}$ \\
\hline R6 & Grão cheio ou completo & $\begin{array}{l}\text { Vagem contendo grãos verdes preenchendo as } \\
\text { cavidades da vagem de um d os } 4 \text { últimos nós do caule, } \\
\text { com folha completamente desenvolvida }\end{array}$ \\
\hline R7 & & Uma vagem normal no caule com coloração de madura \\
\hline $\mathrm{R} 8$ & Maturação plena & 95\% das vagens com coloração de madura \\
\hline
\end{tabular}

Fonte: Adaptado de FARIAS et al. (Circular Técnica 48, 2007)

\subsection{Resultados de pesquisas}

Rezende et al. (2011) avaliando a influência do estádio de colheita sobre a produção e a qualidade do feno das cultivares Conquista e Monsoy 8400, em cinco estádios de maturação (R2, R3, R4, R5 e R6). Concluíram que a cultivar de soja Monsoy 8400 apresenta melhor aptidão para a fenação visto seu maior rendimento de proteína bruta que a cultivar Conquista $\left(1365 \mathrm{~kg} \mathrm{ha}^{-1} \mathrm{e}\right.$ 
$1147 \mathrm{~kg} \mathrm{ha}^{-1}$ respectivamente). Independentemente da cultivar de soja (Conquista e Monsoy 8400), o melhor estádio de maturação foi o de frutificação plena (estádio de desenvolvimento $\mathrm{R} 4)$.

Pádua et al. (2006) avaliando a produção de MS (PMS) e a composição-químico bromatológica de três leguminosas forrageiras: kudzu tropical, macrotiloma e soja perene em dois sistemas de cultivo (tutorado e livre), concluíram que o sistema tutorado apresentou maior produção de matéria seca $\left(7,17 \mathrm{t} \mathrm{ha}^{-1}\right)$ que pela sua complexidade, foi mais indicado para pequenas propriedades, de forma a maximizar os recursos forrageiros, em menor área cultivada. Os teores de PB, FDN e FDA não sofreram alterações dentro dos sistemas de manejo (PB $15,32 \%$ e $16,04 \%$; FDN - 57,45\% e 58,00\%; FDA - 39,99\% e 39,64\%; sistema livre e tutorado respectivamente).

Lima et al. (1972) avaliando o valor nutritivo do feno de soja perene colhida em diferentes estádios de crescimento, estádios vegetativo, de início de floração e de plena floração, concluíram que os fenos correspondentes aos dois primeiros estádios se mostraram com valores maiores de proteína bruta do que a alfafa com o mesmo teor de fibra bruta $(19,6 \%$ e $14,21 \%$ respectivamente), e que não houve diferença significativa entre os coeficientes de digestibilidade da proteína bruta do feno de soja perene nos três estádios de maturação $(73,78 \%$; 69,20\%; $73,53 \%$; respectivamente).

Canto et al. (1998), avaliando a digestibilidade dos fenos de soja anual e capim papuã puros ou em mistura (T1- 100\% soja anual; T2- 67\% soja anual e 33\% capim papuã; T3- 33\% soja anual e $67 \%$ capim papuã; T4- $100 \%$ capim papuã), onde os cortes da soja anual foram realizados durante os estádios R5 a R6, seguido do corte do capim papuã na fase de amadurecimento. Verificaram que os teores de PB decresceram do T1 ao T4 (10,44\% a 4,14\%), enquanto os coeficientes de digestibilidade in vivo da MS e o teor de NDT permaneceram próximos a $47 \%$ para ambos os tratamentos. Verificaram ainda, que conforme aumentavam a participação do feno de papuã, decrescia o valor protéico, e também que os fenos foram considerados de baixa qualidade.

Canto et al. (1992), avaliando cultivares de soja na produção e qualidade do feno, cujas cultivares eram: a) ciclo precoce: (P): BR-2. Paraná, Planalto, IAS-5. b) Ciclo médio (M): CEP12, IAS-4, Bragg, BR-4. c) Ciclo semi-tardio (ST): BR-1, Bossier. d) Ciclo tardio (T): Cobb, Santa Rosa. Observaram que não houve diferença significativa na produção de MS (obtendo média de $8466 \mathrm{~kg} \mathrm{ha}^{-1}$ ) e nem de \%DIVMS para nenhuma das 12 cultivares avaliadas. Houve diferença significativa no teor de PB na MS apenas entre as cultivares BR-1 e Bragg (variando de $12,6 \%$ à $16,67 \%$, respectivamente). 
Carvalho et al. (2017), avaliando a qualidade química de silagem e feno de gliricídia em diferentes alturas de resíduo (70, 90 e $110 \mathrm{~cm})$. Observaram que o feno apresentou maiores teores de $\mathrm{PB}$ em relação à silagem $\left(203,2 \mathrm{~g} \mathrm{~kg}^{-1}\right.$ de $\mathrm{PB}$ para feno e $168,1 \mathrm{~g} \mathrm{~kg}^{-1}$ de $\mathrm{PB}$ para silagem) e não houve diferença estatística de PB na MS entre os tratamentos $\left(185,1^{\mathrm{a}} ; 179,8^{\mathrm{a}} ; 192,0^{\mathrm{a}}\right.$, respectivamente). A gliricídia conservada na forma de feno apresentou melhor qualidade química em relação à silagem.

Bayão et al. (2016), avaliando a composição química e tempo para atingir o ponto de fenação da Leucena e Gliricídia, verificaram que os teores de MS da Gliricídia e Leucena foram: $91,24 \%$ e $91,32 \%$, respectivamente, enquanto os teores de PB foram: $18,64 \%$ e $17,7 \%$. O tempo para atingir o ponto de fenação foi de 16 horas para ambas.

\section{MATERIAL E MÉTODO}

\subsection{Local do experimento}

O experimento foi realizado na safra 16/17, conduzido no sítio das Acácias II, área experimental da Faculdade "Dr. Francisco Maeda" - FAFRAM, município de Ituverava-SP, cujas coordenadas geográficas são: altitude de $605 \mathrm{~m}$, a latitude é de $20^{\circ} 20^{\prime} \mathrm{S}$ e a longitude $47^{\circ}$ 46' W. O solo pertence à classe Latossolo Vermelho Acriférrico típico, vegetação tipo cerrado, relevo plano, muito argiloso, com uma boa drenagem (CARVALHO FILHO, 1999). O clima foi classificado como tipo AW - Megatérmico (tropical úmido) com temperatura média do mês mais frio acima de $18{ }^{\circ} \mathrm{C}$, denominado clima de Savanas, com inverno seco e chuvas máximas de verão (CARRER; GARCIA, 2007). Foram coletadas amostras de solo na camada de 0-20 cm, as quais foram submetidas à análise no laboratório de solos da Faculdade "Dr. Francisco Maeda".

\subsection{Plantio da soja}

O plantio foi realizado no dia 19 de Novembro de 2016. Foi utilizado o cultivar de soja comercial 5G7315IPRO, lote YY00G6226I, categoria S2 e peneira 6,0, sendo semeado no espaçamento de 0,40 metros entre linhas, com estande de 400 mil plantas por hectare.

No tratamento de sementes foram utilizados os seguintes produtos: Potamol ${ }^{\circledR}$ Plus: fertilizante organomineral à base de molibdênio e aminoácidos que melhora o desenvolvimento radicular, melhora o aproveitamento do N-Fertilizante;ROCKS: inseticida de contato, ingestão e sistêmico do grupo químico piretróide e neonicotinóide. 
As sementes foram inoculadas no dia do plantio (19/11/2016) e o inoculante utilizado foi o Biomax ${ }^{\circledR} 10$ que fornece dois milhões de unidades formadoras de colônia (UFC) por semente, em seguida foi aplicado grafite (para separação das sementes).

\subsection{Separação da área}

Após a germinação foi feita a separação da área, onde, cada parcela experimental foi constituída de quatro linhas de cinco metros lineares e que foram avaliadas somente as duas linhas centrais. Foram divididas 20 parcelas, onde cada tratamento tinham quatro repetições. Ao redor das parcelas foi feita uma bordadura de três metros de ambos os lados.

\subsection{Tratos culturais}

No dia 21/12/2016 foi feita a seguinte aplicação: Glizmax Prime $3 \mathrm{~L} \mathrm{ha}^{-1}$ - herbicida não seletivo, de ação sistêmica, do grupo químico glicina substituída, cujo ingrediente ativo é o Isopropylammonium $\mathrm{N}$-(phosphonomethyl) glycinate, de classe III (medianamente toxico ao meio ambiente).

No dia 29/12/2016 foram feitas as seguintes aplicações: Dipel 0,5 $\mathrm{L} \mathrm{ha}^{-1}$ - i.a Bacillus thuringiensis, inseticida biológico de classe IV (pouco perigoso ao meio ambiente); Assist 0,5L $\mathrm{ha}^{-1}$ - inseticida e acaricida de contato, adjuvante, do grupo químico hidrocarbonetos alifáticos, classe IV (pouco perigoso ao meio ambiente); Orkestra SC $0,3 \mathrm{~L} \mathrm{ha}{ }^{-1}$ - fungicida de ação protetora e sistêmica, dos grupos químicos estrobilurina (Piraclostrobina) e carboxamida (Fluxapiroxade), classe III (medianamente tóxico ao meio ambiente); Reduphol Max 0,1L ha ${ }^{-1}$ adjuvante; Talstar 100 EC 0,2 $\mathrm{L} \mathrm{ha}^{-1}$ - inseticida-acaricida de contato e ingestão, piretróide, classe III (medianamente tóxico ao meio ambiente).

\subsection{Tratamentos (cortes)}

O material foi cortado manualmente no campo, os cortes tiveram inicio sempre às 8:00 horas da manhã, à aproximadamente cinco centímetros do solo e em seguida colocado em sacos plásticos.

No dia 23/12/2016 foi realizado o primeiro corte, referente ao estádio de maturação R2. No dia 02/01/2017 foi realizado o segundo corte, referente ao estádio de maturação R3. No dia 12/01/2017 foi realizado o terceiro corte, relacionado ao estádio de maturação R4. No dia 23/01/2017 foi realizado o quarto corte, referente ao estádio de maturação R5. No dia 02/02/2017 foi realizado o quinto e último corte, referente ao estádio de maturação R6. 
Logo após os cortes, a forragem foi levada a um local para secagem, onde foram secos a pleno sol e, chegando ao ponto de feno, foram ensacados novamente e pesados.

\subsection{Características avaliadas}

Foram retiradas amostras de cada uma das repetições de ambos os tratamentos (R2, R3, R4, R5 e R6), que seguiram para análise bromatológica no laboratório da Faculdade "Dr. Francisco Maeda" - FAFRAM, Ituverava- SP, para obter as porcentagens de matéria seca (MS), proteína bruta (PB), fibra em detergente neutro (FDN) e fibra em detergente ácido (FDA) da soja nos cinco estádios de maturação.

\subsection{Análise estatística}

Os dados para análise qualitativa foram submetidos à análise de variância em um delineamento inteiramente casualisado (DIC) com cinco tratamentos e quatro repetições e as médias comparadas pelo teste de Tukey a 5\% de margem de erro.

\section{RESULTADO E DISCUSSÃO}

Os resultados apresentados na Tabela 3 demonstram a análise bromatológica de matéria seca (MS), proteína bruta (PB), fibra em detergente neutro (FDN) e fibra em detergente ácido (FDA) do feno de soja, nos diferentes estádios de maturação avaliados, expressos na \%MS.

Tabela 4. Média dos valores, em percentagem, de matéria seca (MS), proteína bruta (PB), fibra em detergente neutro (FDN) e fibra em detergente ácido (FDA) do feno de soja, Ituverava/SP 2017

\begin{tabular}{cccccc}
\hline Tratamentos & MS\% & PB\% & FDN\% & FDA\% & FENO $\left(\mathrm{kg} \mathrm{ha}^{-1}\right)$ \\
\hline R2 & $88,81 \mathrm{~A}$ & $17,61 \mathrm{~A}$ & $57,91 \mathrm{~A}$ & $38,87 \mathrm{~A}$ & $3812,0 \mathrm{C}$ \\
R3 & $87,71 \mathrm{~A}$ & $17,41 \mathrm{~A}$ & $59,37 \mathrm{~A}$ & $38,76 \mathrm{~A}$ & $4625,0 \mathrm{BC}$ \\
R4 & $78,70 \mathrm{~A}$ & $16,86 \mathrm{~A}$ & $51,80 \mathrm{~B}$ & $37,08 \mathrm{~A}$ & $6875,0 \mathrm{~B}$ \\
R5 & $90,79 \mathrm{~A}$ & $17,66 \mathrm{~A}$ & $59,28 \mathrm{~A}$ & $40,07 \mathrm{~A}$ & $5625,0 \mathrm{BC}$ \\
R6 & $92,72 \mathrm{~A}$ & $18,31 \mathrm{~A}$ & $59,86 \mathrm{~A}$ & $38,70 \mathrm{~A}$ & $16697,5 \mathrm{~A}$ \\
\hline Média Geral & 87,75 & 17,57 & 57,64 & 38,70 & 7525 \\
\hline C.V.\% & 8,45 & 7,26 & 3,83 & 4,18 & 14,37 \\
\hline \multicolumn{5}{c}{ Médias seguidas da mesma letra, na coluna, não diferem estatisticamente entre si. }
\end{tabular}

O teor de matéria seca do feno apresentou média de $87,75 \%$, sendo esse valor indicado para produção de feno. Corroborando, Cruz (1997) cita que deve reduzir seu teor de umidade de 
$70 \%$ a $90 \%$ para $12 \%$ a $15 \%$.

Não houve significância estatística $(\mathrm{p}<0,05)$ entre os teores de matéria seca e proteína bruta dos tratamentos, onde a média de matéria seca e de proteína bruta foram 87,75\% e 17,57\% respectivamente. O que difere do resultado encontrado por Rezende et al. (2011), onde os teores de proteína aumentaram até R4 e R5 e diminui no estádio R6 (os tratamentos R4 e R5 tiveram resultados iguais estatisticamente, 14,73\% e 14,99\% respectivamente; R6 - 12,27\%). Ainda segundo o autor, o corte no estádio R4 foi escolhido como ideal, pela vantagem de possibilitar melhor uso da área com outras culturas em sucessão em decorrência do menor tempo de permanência da soja no campo e também pelo alto rendimento de proteína, altos rendimentos de massa fresca, matéria seca e de feno.

Canto et al. (1998) avaliando a digestibilidade dos fenos de soja anual observaram teor de PB inferior a $12 \%$, que foi muito abaixo do encontrado neste trabalho $(17,57 \%)$.

Entre os teores de fibra em detergente neutro o único que teve diferença estatística foi o tratamento R4, e levando-se em consideração que o FDN representa o consumo, e quanto maior FDN, menor é o consumo e vice versa, o estádio R4 $(51,80 \%)$ se encontra dentro da faixa ideal proposta pela Embrapa Gado de Leite (2017) que fica entre 38 e 54\%.

Os valores referentes ao teor de FDA (que é referente à digestibilidade e é inversamente proporcional, ou seja, quanto maior o teor de FDA, menor a digestibilidade) dos tratamentos não diferiram significativamente, tendo uma média de $38,70 \%$. Onde ambos estão dentro da faixa ideal proposta pela Embrapa Gado de Leite (2017).

O melhor estádio em produção de feno por hectare foi o R6 $\left(16.697,5 \mathrm{~kg} \mathrm{ha}^{-1}\right)$, contudo, seu teor de FDN (59,86\%) ultrapassou a faixa ideal proposta pela Embrapa Gado de Leite (2017), mas, em contrapartida, ao ser comparado com os outros estádios, produziu $10.000 \mathrm{~kg}$ a mais. Também, mesmo sem significância estatística, obteve o maior teor de PB (18,31\%), contrastando com os resultados obtidos por Rezende et al. (2011) e Gris (2008).

\section{CONCLUSÃO}

Com os dados obtidos no presente trabalho, concluiu-se que o estádio de maturação R6 apresentou a melhor opção de corte para fenação no município de Ituverava-SP. Foi o tratamento que apresentou o maior teor proteico e a maior produção de feno em $\mathrm{kg} \mathrm{ha}^{-1}$. 


\section{REFERÊNCIAS}

BAYÃO, G. F. V. et al . Desidratação e composição química do feno de Leucena (Leucena leucocephala) e Gliricidia (Gliricidia sepium). Rev. bras. saúde prod. anim., Salvador, v. 17, n. 3, p. 365-373, Sept. 2016. Available from $<$ http://www.scielo.br/scielo.php?script=sci_arttext\&pid=S1519$99402016000300365 \& \operatorname{lng}=\mathrm{en} \& \mathrm{nrm}=\mathrm{iso}>$. access on 20 Nov. 2017. http://dx.doi.org/10.1590/S1519-99402016000300004.

CRUZ, M. F. R. Avaliação das perdas de valor nutritivo durante o processo de fenação da cultura da alfafa em três propriedades no norte do Paraná. 1997. 71 p. Dissertação (Mestrado) - Escola Superior de Agricultura Luiz de Queiroz, Piracicaba.

CANTO, M. W. do et al. Digestibilidade dos fenos de soja anual e capim papuã puros ou em mistura. Ciência Rural, Santa Maria, v. 28, n. 2, p.309-314, 1998.

COSTA, J. L. DA; RESENDE, H. Produção de feno de gramíneas. Embrapa gado de leite. 2000. (Boletim Técnico).

CARVALHO, C. B. de M. et al . Composição química de silagem e feno de Gliricídia sepium em diferentes alturas de resíduo. Rev. bras. saúde prod. anim., Salvador, v. 18, n. 2, p. 239-248, June 2017 . Available from <http://www.scielo.br/scielo.php? script=sci_arttext\&pid=S1519$99402017000200239 \& \operatorname{lng}=\mathrm{en} \& \mathrm{nrm}=\mathrm{iso}>$. access on 20 Nov. 2017. http://dx.doi.org/10.1590/s1519-99402017000200003.

CANTO, M. W. do; BARRETO, I. L.; PIRES, M. B. G. Avaliação de cultivares de soja na produção e qualidade do feno. Cienc. Rural, Santa Maria, v. 22, n. 3, p. 307-312, Dec. 1992 . Available from <http://www.scielo.br/scielo.php?script=sci_arttext\&pid=S0103-

84781992000300010\&lng=en\&nrm=iso $>$. access on 20 Nov. 2017.

http://dx.doi.org/10.1590/S0103-84781992000300010.

CARRER, T. T.; GARCIA, A. Classificação climática para a cidade de Ituverava/SP. Nucleus, Ituverava, v. 4, n. 1, oct. 2007. ISSN 1982-2278. Disponível em: <http://www.nucleus.feituverava.com.br/index.php/nucleus/article/view/9/36>. Acesso em: 29 nov. 2017.

CARVALHO FILHO, A. Levantamento detalhado e alterações de alguns atributos provocados pelo uso e manejo dos solos da faculdade de Agronomia de Ituverava-SP. Jaboticabal, 1999. 81 f. Dissertação (Mestrando em Agronomia) - Universidade Estadual Paulista. Faculdade de ciências agrárias e veterinárias campus de Jaboticabal, maio 1999.

COSTA, J. L.; RESENDE, H. Qualidade do Feno. EMBRAPA: gado de leite. Disponível em: <http://www.agencia.cnptia.embrapa.br/Agencia8/AG01/arvore/AG01_330_217200392414.html. >. Acesso em: 13 nov. 2017.

EVANGELISTA, A. R. Silagem de milho ou sorgo com soja. Lavras: ESAL, 1986. 19 p. (Boletim Técnico).

EMBRAPA - EMPRESA BRASILEIRA DE PESQUISA AGROPECUÁRIA. Tecnologias de produção de soja - região central do Brasil - 2005. Londrina: EMBRAPA Soja: EMBRAPA Cerrados: EMBRAPA Agropecuária Oeste: Fundação Meridional, 2004. 239 p. 
FARIAS, J. R. B.; NEPUMOCENO, A. L.; NEUMAIER, N. Ecofisiologia da soja. Londrina: Embrapa, 2007. 9 p. (Circular Técnica 48).

GRIS, C. F. et al . Épocas de corte e cultivares na composição mineral de feno de soja [Glycine $\max ($ L.) Merrill]. Ciênc. agrotec., Lavras , v. 32, n. 2, p. 413-419, abr. 2008.

LIMA, C. R.; SOUTO, S. M. Valor nutritivo do feno proveniente de diferentes estádios de crescimento da cultura de soja perene (Glycine javanica). 1972. Disponível em: < https://seer.sct.embrapa.br/index.php/pab/article/view/17424/11687 >. Acesso em: 13 nov. 2017.

MARTHA JÚNIOR, G. B.; CORSI, M. Pastagens no Brasil: situação atual e perspectivas. Preços agrícolas, Piracicaba, v. 15, n. 170, p. 3-6, jan. 2001.

PADUA, F. T. de et al . Produção de matéria seca e composição químico-bromatológica do feno de três leguminosas forrageiras tropicais em dois sistemas de cultivo. Cienc. Rural, Santa Maria , v. 36, n. 4, p. 1253-1257, ago. 2006 .

REIS, R. A.; RODRIGUES, T. de J. D. In: SIMPOSIO SOBRE ECOSSISTEMAS DE PASTAGEM, 2., 1993, Jaboticabal. Anais... Jaboticabal: UNESP, 1993. p. 17-61.

REIS, R. A.; MOREIRA, A. L.; PEDREIRA, M. dos S. Técnicas para produção e conservação de fenos de forrageiras de alta qualidade. In: SIMPÓSIO SOBRE PRODUÇÃO E UTILIZAÇÃO DE FORRAGENS CONSERVADAS, 1., 2001, Maringá. Anais.... Maringá: UEM/CCA/DZO, 2001. p. 1 - 30.

REZENDE, A.V. et al. Efeito da densidade de semeadura e composição bromatológica de silagem de girassol (Helianthus annus L.). Lavras - MG, Ek-pekc" g"Citqvgepqnqikc, Edição especial, p.1672-1678, 2003.

REZENDE, P. M.et al. Cultivares e estádios de colheita no rendimento forrageiro da soja. Lavras - MG, Revista Agrogeoambiental. Abr.2011.

SILVA, M. S. J. da et al. Estimativa de produção e valor nutritivo do feno de estilosantes cv. Campo Grande. Semina: Ciências Agrárias, [s.1.], v. 34, n. 3, p.1363-1379, 24 jun. 2013.

Universidade Estadual de Londrina. http://dx.doi.org/10.5433/1679-0359.2013v34n3p1363.

VILELA, D. Feno. Informe Agropecuário, Belo Horizonte, v.9, n.108, p.29-31, 1983.

VILELA, D. Sistemas de Conservação de Forragem. 2) Fenação. Coronel Pacheco: EMBRAPA, 1984. 31 p. Boletim Técnico, 7.

VILELA, H. Feno e Fenação. Disponível em:

<http://www.agronomia.com.br/conteudo/artigos/artigos_feno_fenacao.htm>. Acesso em: 25 jul. 2017. 